\title{
FROM TOOL-MAKING TO TOOL-USING - AND BACK: RATIONALES FOR ADOPTION AND USE OF LCC
}

\author{
Pernilla GLUCH ${ }^{1, *}$, Mathias GUSTAFSSON², Henrikke BAUMANN², Göran LINDAHL ${ }^{2}$ \\ ${ }^{1}$ Division of Service Management and Logistics, Department of Technology Management and Economics, \\ Chalmers University of Technology, Göteborg, Sweden \\ ${ }^{2}$ Division of Construction Management, Department of Architecture and Civil Engineering, \\ Chalmers University of Technology, Göteborg, Sweden \\ ${ }^{3}$ Division of Environmental Systems Analysis, Department of Technology Management and Economics, \\ Chalmers University of Technology, Göteborg, Sweden
}

Received 2 January 2017; accepted 14 July 2017

\begin{abstract}
Real estate- and property owners' rationales behind the adoption of Life Cycle Costing (LCC) respectively how LCC is actually used in renovation projects, is investigated through empirical data from a questionnaire survey sent to managers in Swedish real estate organisations. The study shows a positive attitude towards LCC. It is perceived to as a flexible and multi-functional tool with a familiar monetary format. Nevertheless, the study also reveals simplistic and undeveloped views of how to use LCC. While much research has focused on developing sophisticated LCC tools, the findings indicate that practitioners' interest in these refinements seems limited. The importance of understanding that LCC is used in a context of multiple and partly competing institutional logics of renovation is emphasised. The paper contributes to a more informed research in development of LCC tools as well as better informed LCC use among real estate and property owners.
\end{abstract}

Keywords: Life cycle costing (LCC), project management, property management, renovation, real estate, questionnaire, Sweden.

\section{Introduction}

The increasing need for the construction and real estate industry to take greater strategic and long-term responsibility by improving the environmental performance of buildings is accompanied with an increasing body of research on economic evaluation for sustainable building, principally related to Life Cycle Cost (LCC) (cf. Goh \& Sun, 2016; Caccavelli, Krigsvol, Thamling, \& Jaarto, 2005). LCC has been suggested as helpful as a way of thinking in strategic management (Schaltegger, Müller, \& Hindrichsen, 1996). Thus, LCC is useful for including long-term consequences from decisions, which in turn involves having a strategic view on the product, in the case of this paper a property. While LCC has existed for more than four decades and despite well-documented benefits of LCC as a means for including long-term economic consequences in building investment decisions, recent research claims that the adoption of LCC within industry is slow (Higham, Fortune, \& James, 2015; D'Incognito, Costantino, \& Giovanni, 2015). Various barriers have been identified, such as lack of data (Oduyemi, 2015), lack of tool awareness (Olsson, Malmqvist, \& Glaumann, 2015), short-term horizons on building investments (Higham et al., 2015) and lack of knowledge on sustainability issues among practitioners (Häkkinen \& Belloni, 2011; Olsson et al., 2015). One way forward suggested by Häkkinen and Belloni (2011) is to improve the understanding about procedural difficulties, who the involved actors are and their practical use of these tools.

Even though practitioners are the intended users of the developed tools and methods, their views and descriptions of the practice of LCC are remarkably absent in the research literature (Korpi \& Ala-Risku, 2008). Thus, the actual adoption and use of LCC seem to be taken for granted as a consequence following the development of models and tools. The question arises whether or not the adoption of LCC really is as slow as claimed, or if there is a discrepancy between the way researchers idealistically picture how LCC should be used and practitioners'

*Corresponding author. E-mail: pernilla.gluch@chalmers.se 
ways of using LCC in practice. In a recent study about construction clients it was in fact found that the vast majority used LCC within their organization (Gluch \& Gustafsson, 2015), which agrees with the interview observations made by Olsson et al. (2015). However, Olsson et al. (2015) found a large variation in the way LCC was used. Taken together, this points to a disparity between researchers' and practitioners' perception about the level and type of use of LCC in construction and real estate, necessitating the investigation about the practice of LCC, including practitioners' rationales for LCC adoption and a mapping of their uses for it in practice. Such improved understanding would contribute to a more informed research for LCC tool development as well as a more informed LCC use by practitioners in real estate companies.

Renovation is an area for which LCC are particularly applicable. Sustainable renovation is seen as a key for meeting goals related to, for example, decarbonization (Mjörnell, Boss, Lindahl, \& Molnar, 2014) and reduced total energy consumption of buildings (Ástmarsson, Jensen, \& Maslesa, 2013). Renovation is currently also a major challenge for Swedish real estate and property owners since there is great need to transform an aging, energyinefficient and unsustainable building stock in an economically feasible way (Thuvander, Femenias, Mjörnell, \& Meiling, 2012; Palm \& Reindl, 2016). There is therefore an increased need for life cycle perspectives during renovation processes (Olsson, Malmqvist, \& Glaumann, 2016).

The potential for control over life cycle costs is claimed to be greatest in early stages of the design process (Higham et al., 2015; Olsson et al., 2016), which is why real estateand property owners in their role as construction clients are an important target group for LCC use (Opoku \& Ahmed, 2014). The client is repeatedly put forward as the key actor and driver for the establishment of an active sustainability practice (Häkkinen \& Belloni, 2011; Higham et al., 2015; D’Incognito et al., 2015).

The aim of this paper is to improve understanding about real estate- and property owner's attitudes regarding long-term thinking and how they use LCC in practice. More specifically, the objective is to survey how they as renovation clients use LCC as a tool for making renovation decisions. This includes an investigation of rationales for LCC use on managerial, operational, individual and instrumental levels as well as the role of LCC in decision processes for building renovation. The paper contributes with valuable knowledge for researchers regarding the role and function of LCC in practice, thereby complementing the large research streams on tool/method development and the case-based research that today dominate LCC research (Korpi \& Ala-Risku, 2008).

\section{An overview of research: life cycle costing (LCC) development and practice}

In theory, LCC and similar tools, such as Whole Life Cost (WLC), Total Cost Assessment (TCA) and Life Cycle Cost Assessment (LCCA), encourages taking a long-term per- spective in decision-making processes rather than a shortterm focus on lowering initial acquisition costs (Woodward, 1997). For a comprehensive summary of various tools in terms of similarities and differences see Gluch and Baumann (2004, p. 573). Since investment costs are set against running costs over a longer period of time than in traditional investment calculus, LCC enables choices between solutions set in relation to a building's full technical life cycle. For an LCC to capture all costs through the life cycle of a building, it must include data on capital costs, estimated maintenance, operating and disposal costs, predicted lifetime of the building and of various building components (Olsson et al., 2015). Owing to the extended time horizon in the calculations, it increases the importance of how future uncertainties are properly addressed (Korpi \& Ala-Risku, 2008), which is why assumptions on discount rates, alternative scenarios and cost allocation over time need careful consideration (Gluch \& Baumann, 2004). In short, there are many parameters with several options, opening up for alternative approaches in practice. To handle this variety, standardization as well as customization have been suggested as strategies for promoting LCC application.

Goh and Sun (2016) reviewed 27 articles in four key construction management journals and eight books. In their chronological review of LCC for buildings, they tracked and described the evolution of LCC. Although LCC and other similar decision support tools, such as Whole Life Costing, has been available since early 1970s, the notion of a green LCC emerged around year 2000 and has since gained ground as 'today's mainstream LCC' (Goh \& Sun, 2016). LCC is often proposed as a way to overcome deficiencies in current application of sustainability considerations in decisions and actions (e.g. Park, 2009). Goh and Sun (2016) noticed that although standardization of input parameters has been proclaimed since the infancy of LCC, and in fact are available, there is still a large divergence regarding assumptions on time and uncertainty affecting predictions on future cost consequences in the calculations. Thus, the greening of LCC is highly dependable on the ambition and purposive choices of the calculator and/or user of LCC.

In another review on the intersection of LCC and management/decision-making in the context of buildings and properties, Gluch (2014) covered 60 journal articles published between 2003 and 2013. She observed that much research concerns tool-making, either various types of modelling (e.g. Brown, Malmqvist, Bai, \& Molinari, 2013; Ding, 2008; Morrissey, Meyrick, Sivaraman, Horne, \& Berry, 2012; Flores-Colen \& de Brito, 2010; Sharma, Saxena, Sethi, \& Shree, 2011), or method and/or tool development (e.g. Kirkham, 2005; Wang, Chang, \& Nunn, 2010; Love \& Bullen, 2009; Kaklauskas, Zavadskas, \& Raslanas, 2005; Junghans, 2013; Arja, Sauce, \& Souyri, 2009; Brown et al., 2013; Risholt, Time, \& Hestnes, 2013; Zhang, Platten, \& Shen, 2011). Gluch (2014) noted that the models often were multi-dimensional to capture the complexities of these types of decisions (e.g. Wang, Zmeu- 
reanu, \& Rivard, 2005; Ding, 2008; Sharma et al., 2011; Swarr et al., 2011, Brown et al., 2013; Mjörnell et al., 2014), thereby reflecting an 'objectively determined' functionalist view towards application, similarly to what Rex and Baumann (2008) noted for the development and application of another life cycle tool, environmental life cycle assessment (LCA). The LCC models, calculation methods and/ or tools designed by researchers were then often tested in one or more real cases (e.g. Arja et al., 2009; Brown et al., 2013; Risholt et al., 2013; Zhang et al., 2011). Gluch (2014) concluded that most researchers justify their efforts with practitioners' need for 'customized' LCC, however, without empirical support about the nature of the need. Thus follows a situation where researchers continue to develop methods that package uncertainty, complexity and bounded rationality into optimized monetary figures, while it remains unclear to what extent LCC actually supports practical decision-making.

Studying the development of a customized LCC tool, Ludvig (2013) found that LCC was not used in accordance with the blueprints in the handbooks (e.g. Farr, 2011; Dhillon, 2013) nor the standards (e.g. ISO 15686 :5). She also found differences in managers' perception on the benefits of using LCC to capture sustainability. Moreover, the function of LCC differed across construction projects as well as between LCC users. Korpi and Ala-Risku (2008) made similar observations from their review on LCC application with a client perspective. Several of the reviewed articles made complaints about the shortage of standards and formal procedures, despite the existence of commercial standards.

Based on a review of 55 case studies described in academic journal articles, Korpi and Ala-Risku (2008) concluded that the current research is unhelpful for guidance on how to incorporate LCC into practice. The case studies did not build on previous LCC research discourse, resulting in a highly disconnected and fragmented description. Moreover, the reports on LCC methods were unsatisfactory concerning the reporting of life cycle phases considered, information sources used, cost estimation methods used and the nature of analyses done. A systematic understanding on the usability of LCC was limited by the majority of studies being one-off case studies in which LCC tools/methods were either developed or tested to confirm the superiority of a specifically suggested technical solution. Concerning LCC practice, Korpi and AlaRisku (2008) observed that cost estimations were based on expert judgement and analogy rather than on statistical methods without going into detail. Also, deterministic life cycle costs were used in the calculations instead of sensitivity analysis. In half of the cases studies, uncertainty in future costs was not considered - in the other half, it was considered by using discount rate. Internal cost databases were missing, resulting in calculations having to rely on external sources of data.

The literature overview shows tool-making's respectively tool-use's different views on LCC applications.
Whereas tool-making seems to presume control of multiple dimensions during application, tool use takes place even when data are lacking and with various simplifications to the method. This raises a number of questions for further inquiry. A first set of questions relates to real estate- and property owners' attitudes regarding long-term thinking and LCC in renovation projects:

- What rationales are presented as triggers for deciding to conduct an LCC?

- How does long-term, life cycle thinking as integrated in project management routines affect LCC rationales on different levels (managerial, operational, individual and instrumental)?

Another set of questions relates to the actual LCC practice in decision processes for building renovation:

- Who makes the calculations and is the sender of the results from it?

- Who are receivers of the results?

- Where do data come from?

- Which assumptions are made and how is uncertainty dealt with?

\section{Research design and method}

A questionnaire survey was designed to investigate aspects related to real estate- and property owners' attitudes towards and experiences of using LCC in renovation decisions.

\subsection{Questionnaire survey design}

The questionnaire survey had 20 main questions, which focused on three key themes:

1. Life cycle thinking;

2. Decision makers' attitudes to the use of LCC;

3. LCC practice in renovation projects.

The first theme of questions was used to identify two respondent groups - one that has integrated life cycle thinking in renovation project routines and one that has not - which thereafter was compared to each other. Questions about the rationales behind using LCC were partly designed in accordance with the Technology Acceptance Model (TAM) and partly based on previous research on barriers towards adoption of LCC. TAM explains the adoption of various types of technical systems and applications (Davis, 1989) and has been used to explain tool uptake in various types of contexts, such as office tools, software tools and business application tools, as well as various technological systems and applications (see review in Legris, Ingham, \& Collerette, 2003). TAM has in a previous study been found useful for describing and understanding factors influencing LCC use (Gluch \& Gustafsson, 2015). In brief, TAM explores external influence, perceived usability, attitudes towards use and intention to use.

The survey results are structured on four analytical levels, covering managerial, operational, individual and instrumental rationales for adoption and use of LCC. 
Respondents' opinions were measured using a Likert scale with a six-point range (4 questions), a binary scale only with, yes or no answers (5 questions), several response options (8 questions), descriptive information (2 questions) and ranking alternatives (1 question). In using a 6-point scale, we forced the respondents do be more thoughtful and thus becoming more discriminating when answering. It also eliminates possible misinterpretations of the mid-point.

Since a random sample of decision makers in the built environment would not produce sufficient results, purposive sampling was done, aiming to obtain a broad representation of LCC use. The questionnaire was sent to individuals working in 105 Swedish real estate organizations that own and/or manage properties on a long-term basis (state, municipal, and private). The targeted respondents were individuals likely to be involved in building renovation decisions and assumed to be in position to influence their company's long-term environmental and economic sustainability. These were specialized energy strategists, CEOs, division managers, property/facility managers, technical development managers, construction project managers, or sustainability/environmental managers, depending on the organizational structure.

Respondents were identified in two ways. For nine organizations, contact persons provided a list of individuals matching the criteria listed above. For the remaining majority, we used Statistics Sweden's business register, selecting real estate owners and real estate management companies (NACE code 68.2 and 68.32) with more than 50 employees. Respondents were thereafter identified through each company's official web page. This brought a final sample population of 217 individuals.

\subsection{Data collection and final population}

Data were collected in September-November 2013. The questionnaire and two reminders were sent by e-mail using an online questionnaire. The questionnaire was pretested by two managers in order to identify and reduce potential misinterpretations. For the same reason, an instructional cover letter with detailed information about the study was presented in the e-mail and the questionnaire document.
Responses were obtained from 96 individuals of the sample of 217. 66 respondents answered questions pertaining to all three themes. 42 respondents with practical experience of LCC in a renovation project took the part of the questionnaire elaborating on their LCC use in practice.

The distribution of the respondents' occupational title was as follows: construction project manager (32\%), sustainability/environmental manager (19\%), CEO/division manager (14\%), technical development manager (14\%), property manager (12\%), and energy strategist (9\%).

The analysis was conducted using SPSS ${ }^{\circledast}$. For Likert scale variables, mean values were calculated. The robustness of using parametric testing on data from Likert scales have been demonstrated in previous research (Carifio \& Perla, 2007).

\section{Results and analysis}

This results presents rationales behind using LCC on managerial, operational, individual and instrumental levels. Descriptive data are presented in terms of mean values for all respondents. In the analysis, the respondents were divided into two groups depending on if they have included life cycle management into their project management routines (group A) or not (group B). $60 \%$ of the respondents belong to group A and $40 \%$ to group B. This enables us to investigate if this integration has had effect on attitudes towards adopting LCC. For the investigation of actual LCC practice, the results also present how real estate- and property owners conduct an LCC in renovation projects. This includes questions such as; who makes the calculations, who are receiver of the LCC calculations, and what assumptions are made and what key input parameters are used.

\subsection{Life-cycle thinking in project management routines}

Integration of life-cycle thinking in procedures for project management depended on the extent to which long-term solutions were favoured in the organisation but also on project managers' opportunities to contribute to longterm strategic decisions and ability to have an overview, as well as the project team's knowledge (Table 1).

Table 1. Stated reasons for having or not having integrated life-cycle thinking in procedures for project management

\begin{tabular}{|c|c|c|c|c|c|c|}
\hline \multirow{2}{*}{ Question } & \multicolumn{3}{|c|}{ Yes } & \multicolumn{3}{|c|}{ No } \\
\hline & $\mathrm{N}$ & $\mathrm{M}$ & Sd & $\mathrm{N}$ & M & Sd \\
\hline Knowledge is in the project team ${ }^{\star}$ & 60 & 4.54 & .91 & 38 & 3.82 & 1.58 \\
\hline $\begin{array}{l}\text { Project managers actively contribute to the organization's } \\
\text { long-term strategic decisions }{ }^{*}\end{array}$ & 60 & 4.53 & .93 & 37 & 3.57 & 1.57 \\
\hline Project managers have necessary overview ${ }^{\star}$ & 60 & 4.21 & .96 & 38 & 3.79 & 1.51 \\
\hline $\begin{array}{l}\text { Project management functions and strategic functions are } \\
\text { integrated with each other }\end{array}$ & 60 & 3.97 & 1.28 & 37 & 3.76 & 1.42 \\
\hline $\begin{array}{l}\text { Running operation costs for facility management is } \\
\text { treated jointly with long-term investment costs* }\end{array}$ & 60 & 4.28 & 1.35 & 36 & 2.78 & 1.71 \\
\hline Long-term solutions are favoured ${ }^{*}$ & 60 & 4.55 & 1.14 & 37 & 4.14 & 1.77 \\
\hline
\end{tabular}

${ }^{*}$ Difference significant at $\mathrm{p}<.05$ using $\mathrm{t}$-test.

For the No group questions were phrased in a negating form (values then reversed for comparison). The scale ranges from 1 (strongly disagree) to 6 (strongly agree). 
Regarding integration of life-cycle thinking in project management routines, there was a statistically significant difference between the two groups for all statements except: Project Management functions and strategic functions are integrated with each other. Favouring long-term solutions is valued higher among group A than the B group. The project team and the project manager's knowledge are also valued as more important within group $\mathrm{A}$ than for group B. In addition, project managers' opportunity to actively contribute to the organization's long-term strategic decisions was valued higher in group A. Thus, good understanding and knowledge of these issues within the project team is seen as key to greater long-term emphasis in renovation projects. For group B, integrated handling of operation costs and investment costs (different bags of money) scored the lowest, indicating that this may be a cause of integration not taking place (Table 1).

\subsection{Extent of LCC use in property owners' renovation projects}

A large majority (64\%) of respondents $(\mathrm{N}=93)$ indicate that LCC has been used or discussed within the organization only within the past 5 years. Of these $5 \%$ less than a year. 23\% state LCC has been known within the organization longer than 5 years but less than 15 years. Only 5\% state that it has been known longer than 15 years. Nine percent of the respondent state that LCC is neither used nor discussed in their organization.

When it comes to the number of renovation projects where LCC calculations were used as part of the decision support foundation $(\mathrm{N}=83)$, respondents answered across the entire scale. One third, $33 \%$, indicate that they in more than $50 \%$ of projects have used LCC. $4 \%$ of these states they use LCC in all project. About one fourth of the respondents, $24 \%$, reported that more than $25 \%$ but less than $50 \%$ of the projects consider LCC. $38 \%$ answered that LCC calculations are done in less than $25 \%$ of the projects. To this question, $5 \%$ of the respondents, state that they do not calculate LCC in any construction project at all. An analysis of answers to these two questions on time and number of projects shows a possible relation between how long LCC has been a known subject in the organization, and the proportion of renovation projects where it is actually applied $(r=.20, p=.07)$.

\subsection{Rationales for adopting LCC}

The results are structured in relation to rationales on four analytical levels; managerial, operational, individual and instrumental.

\section{Managerial level}

Use of different types of tools often respond to demands from the organization or the industry. The mean value for the total dataset presented in Table 2 shows that there is no impact variable on managerial level that stands out as extraordinary in terms of driving the use of LCC in a renovation context. There are individual variations within the results but in terms of mean value the influence from external impact variables are moderate. That the organization and/or management advocate the use of LCC stands out as significantly more influential for group A than for group B. This is also the case for rationales driven by requirements and managerial demands. There also seems to be a driving effect that other colleagues and others in the industry use LCC. The latter is especially seen as a rationale for group B.

\section{Operational level}

The respondents were asked to indicate how they felt about different statements related to the usefulness of conducting an LCC in their daily work. From the results presented in Table 3 we can see that there seem to be quite good conditions for the use of LCC. Lack of resources in terms of finance and time, often highlighted in research as obstacles for a wider use of LCC, seem not be perceived as a major problem in our survey. It should be noted that group A sees statistically less hindrance due to time and money than group B. The actual terminology and apparatus of LCC is at least partly considered as consistent and familiar for many of the respondents, especially for group A although the difference is not statistically significant. Group A believes that the idea of LCC lies rather well in line with how they normally work while group B believe less so. LCC is for both groups considered to be sufficiently flexible. In addition, LCC is also perceived to make it easier to identify key information needed when making decisions on renovation of buildings and properties. This is especially forwarded as a rationale for group B. However,

Table 2. Perceived rationales or non-rationales for LCC use on a managerial level (external impact)

\begin{tabular}{|c|c|c|c|c|c|c|c|c|c|}
\hline \multirow{2}{*}{ Question } & \multicolumn{3}{|c|}{ Total } & \multicolumn{3}{|c|}{ Group A } & \multicolumn{3}{|c|}{ Group B } \\
\hline & $\mathrm{N}$ & M & $\mathrm{Sd}$ & $\mathrm{N}$ & M & $\mathrm{Sd}$ & $\mathrm{N}$ & M & Sd \\
\hline The organization advocates the use of $\mathrm{LCC}^{*}$ & 70 & 3.90 & 1.58 & 44 & 4.39 & 1.38 & 26 & 3.08 & 1.57 \\
\hline My colleagues believe that LCC is a good tool & 69 & 3.77 & 1.47 & 43 & 4.00 & 1.38 & 26 & 3.38 & 1.55 \\
\hline Many within the industry use LCC & 70 & 3.59 & 1.19 & 44 & 3.57 & 1.21 & 26 & 3.62 & 1.17 \\
\hline It is a requirement to use $\mathrm{LCC}^{\star}$ & 70 & 3.54 & 1.82 & 44 & 3.93 & 1.72 & 26 & 2.88 & 1.82 \\
\hline My managers think I should use LCC ${ }^{*}$ & 67 & 3.45 & 1.62 & 41 & 3.93 & 1.49 & 26 & 2.69 & 1.54 \\
\hline Many others within the company use LCC ${ }^{*}$ & 69 & 2.97 & 1.48 & 43 & 3.42 & 1.38 & 26 & 2.23 & 1.37 \\
\hline
\end{tabular}

${ }^{*}$ Difference significant at $\mathrm{p}<.05$ using $\mathrm{t}$-test.

The scale runs from 1 (strongly disagree) to 6 (strongly agree). 
Table 3. Perceived rationales or non-rationales for LCC use on an operational level (usefulness)

\begin{tabular}{|c|c|c|c|c|c|c|c|c|c|}
\hline \multirow{2}{*}{$\begin{array}{c}\text { Question } \\
\text { I perceive that... }\end{array}$} & \multicolumn{3}{|c|}{ Total } & \multicolumn{3}{|c|}{ Group A } & \multicolumn{3}{|c|}{ Group B } \\
\hline & $\mathrm{N}$ & M & $\mathrm{Sd}$ & $\mathrm{N}$ & M & Sd & $\mathrm{N}$ & M & Sd \\
\hline ...there are several different ways to conduct an LCC (flexibility) & 63 & 4.16 & 1.07 & 40 & 4.10 & 1.10 & 23 & 4.26 & 1.01 \\
\hline ...the terminology in LCC is familiar to me & 64 & 4.11 & 1.44 & 41 & 4.27 & 1.38 & 23 & 3.83 & 1.53 \\
\hline ...the terminology in LCC is consistent & 63 & 3.87 & 1.25 & 40 & 4.05 & 1.30 & 23 & 3.57 & 1.12 \\
\hline ...LCC makes it easier to identify key information & 63 & 3.78 & 1.28 & 40 & 3.60 & 1.32 & 23 & 4.09 & 1.16 \\
\hline ...I do not have to adjust my way of working to do an LCC $^{\star}$ & 62 & 3.60 & 1.27 & 39 & 3.87 & 1.30 & 23 & 3.13 & 1.10 \\
\hline ...to learn how to use LCC is easy & 69 & 3.49 & 1.29 & 43 & 3.56 & 1.42 & 26 & 3.38 & 1.06 \\
\hline ...I have necessary resources to do an LCC calculation & 63 & 3.46 & 1.48 & 40 & 3.65 & 1.49 & 23 & 3.13 & 1.42 \\
\hline ...I can adjust LCC so it serves the purpose I am interested in & 63 & 3.41 & 1.20 & 40 & 3.40 & 1.22 & 23 & 3.43 & 1.20 \\
\hline ...I have got profound guidance on $\mathrm{LCC}^{\star}$ & 64 & 3.06 & 1.67 & 41 & 3.39 & 1.59 & 23 & 2.48 & 1.68 \\
\hline ... it is too expensive to do an $\mathrm{LCC}^{*}$ & 62 & 2.10 & 1.08 & 39 & 1.82 & 1.02 & 23 & 2.57 & 1.04 \\
\hline ... it takes too much time to do an $\mathrm{LCC}^{*}$ & 62 & 2.31 & 1.05 & 39 & 2.10 & 1.02 & 23 & 2.65 & 1.03 \\
\hline ...lack of cooperation between involved parties makes LCC difficult ${ }^{*}$ & 62 & 2.65 & 1.32 & 39 & 2.38 & 1.29 & 23 & 3.09 & 1.28 \\
\hline ...input data for LCC calculations are missing & 62 & 2.84 & 1.28 & 41 & 2.78 & 1.27 & 21 & 2.95 & 1.32 \\
\hline ...input data for LCC calculations are unreliable & 61 & 2.89 & 1.22 & 40 & 2.75 & 1.15 & 21 & 3.14 & 1.35 \\
\hline
\end{tabular}

* Difference significant at $\mathrm{p}<.05$ using t-test.

The scale ranges from 1 (strongly disagree) to 6 (strongly agree).

this is somewhat contradictory since they state that they are less familiar with the LCC terminology than Group A. The two groups also differ in respect to perceived lack of cooperation between involved parties were Group B tend to see this as more of an obstacle than group A.

\section{Instrumental level}

Table 4 shows that respondents believe LCC serves a relatively large number of functions in the organization's decision-making processes. Several of these can be linked to a key idea and the textbook picture of how LCC can be used, that is, identifying the most cost effective choice in a long-term perspective and give a comparative eco- nomic view of the various investment options. LCC are also believed to consider energy costs and enable longterm planning.

Moreover, side effects such as greater credibility for the decision, facilitator of communication and learning effects, are also seen as resulting from using LCC. The lowest rated function is using LCC in negotiations, as checklist and for monitoring on-going projects. The two groups have a rather coherent view on LCCs instrumental function and only differ statistically in regard to LCCs role for internal discussions about renovation and LCC as mean to steer investments into a desired direction. Group B sees these effects from LCC as less prominent.

Table 4. Perceived rationales or non-rationales for LCC use on an instrumental level (function)

\begin{tabular}{|c|c|c|c|c|c|c|c|c|c|}
\hline \multirow{2}{*}{$\begin{array}{l}\text { Question } \\
\text { LCC... }\end{array}$} & \multicolumn{3}{|c|}{ Total } & \multicolumn{3}{|c|}{ Group A } & \multicolumn{3}{|c|}{ Group B } \\
\hline & $\mathrm{N}$ & $\mathrm{M}$ & $\mathrm{Sd}$ & $\mathrm{N}$ & $\mathrm{M}$ & $\mathrm{Sd}$ & $\mathrm{N}$ & $\mathrm{M}$ & Sd \\
\hline ...shows what is most cost effective in the long term & 80 & 4.80 & 1.06 & 52 & 4.94 & 0.89 & 28 & 4.54 & 1.29 \\
\hline ...provides greater credibility for decisions & 80 & 4.59 & 1.25 & 52 & 4.62 & 1.14 & 28 & 4.54 & 1.45 \\
\hline ...provides a comparative basis for different investment alternatives & 79 & 4.54 & 1.23 & 52 & 4.71 & 1.09 & 27 & 4.22 & 1.42 \\
\hline ...considers rising energy costs & 79 & 4.49 & 1.18 & 52 & 4.52 & 1.15 & 27 & 4.44 & 1.25 \\
\hline ...provides an economic estimate useful for decision-making & 80 & 4.46 & 1.27 & 52 & 4.63 & 1.09 & 28 & 4.14 & 1.53 \\
\hline ...allows for long-term planning & 79 & 4.30 & 1.22 & 52 & 4.37 & 1.16 & 27 & 4.19 & 1.36 \\
\hline ...is useful in internal discussions about renovation* & 79 & 4.23 & 1.11 & 52 & 4.48 & 0.98 & 27 & 3.74 & 1.20 \\
\hline ...directs investments in a desired direction ${ }^{*}$ & 79 & 4.22 & 1.17 & 52 & 4.48 & 0.90 & 27 & 3.70 & 1.46 \\
\hline ...facilitates communication about long-term consequences & 80 & 4.15 & 1.24 & 52 & 4.23 & 1.15 & 28 & 4.00 & 1.41 \\
\hline $\begin{array}{l}\text {...contributes to learning when collecting information and } \\
\text { making assumptions and estimates for the calculation }\end{array}$ & 79 & 4.01 & 1.25 & 52 & 4.04 & 1.15 & 27 & 3.96 & 1.43 \\
\hline ...is useful in discussions with external stakeholders & 79 & 3.99 & 1.17 & 52 & 4.12 & 1.20 & 27 & 3.74 & 1.10 \\
\hline ...maps future cost items & 80 & 3.98 & 1.34 & 52 & 4.04 & 1.28 & 28 & 3.86 & 1.46 \\
\hline ...enables monitoring of ongoing projects & 79 & 3.66 & 1.31 & 52 & 3.71 & 1.36 & 27 & 3.56 & 1.22 \\
\hline ...calculations are useful in negotiations & 80 & 3.43 & 1.49 & 52 & 3.35 & 1.61 & 28 & 3.57 & 1.26 \\
\hline ...provides a checklist & 78 & 3.18 & 1.39 & 52 & 3.25 & 1.40 & 26 & 3.04 & 1.40 \\
\hline
\end{tabular}

* Difference significant at $\mathrm{p}<.05$ using t-test.

The scale ranges from 1 (strongly disagree) to 6 (strongly agree). 
Table 5. Perceived rationales or non-rationales for LCC use on an individual level (attitude)

\begin{tabular}{|c|c|c|c|c|c|c|c|c|c|}
\hline \multirow{2}{*}{$\begin{array}{c}\text { Question } \\
\text { I perceive that... }\end{array}$} & \multicolumn{3}{|c|}{ Total } & \multicolumn{3}{|c|}{ Group A } & \multicolumn{3}{|c|}{ Group B } \\
\hline & $\mathrm{N}$ & M & $\mathrm{Sd}$ & $\mathrm{N}$ & M & $\mathrm{Sd}$ & $\mathrm{N}$ & M & Sd \\
\hline ...LCC is valuable for me & 63 & 4.57 & 1.17 & 41 & 4.51 & 1.16 & 22 & 4.68 & 1.21 \\
\hline ...I like the idea of using LCC & 63 & 4.54 & 1.24 & 40 & 4.33 & 1.29 & 23 & 4.91 & 1.08 \\
\hline ...calculating LCC gives me increased control & 62 & 4.21 & 1.16 & 40 & 4.38 & 1.13 & 22 & 3.91 & 1.19 \\
\hline ...LCC provide me with relevant information & 63 & 4.21 & .94 & 41 & 4.29 & 0.84 & 22 & 4.05 & 1.09 \\
\hline ...LCC is a suitable tool for doing my job & 63 & 4.16 & 1.08 & 41 & 4.17 & 1.07 & 22 & 4.14 & 1.13 \\
\hline ...LCC gives me profound information & 62 & 3.97 & 1.12 & 40 & 4.08 & 1.12 & 22 & 3.77 & 1.11 \\
\hline ...LCC provides information when I need it & 61 & 3.95 & 1.18 & 39 & 4.03 & 1.25 & 22 & 3.82 & 1.05 \\
\hline ...LCC gives me correct information & 62 & 3.87 & 1.12 & 40 & 4.03 & 1.03 & 22 & 3.59 & 1.26 \\
\hline ...I have enough knowledge to do an LCC & 64 & 3.53 & 1.44 & 41 & 3.66 & 1.41 & 23 & 3.30 & 1.49 \\
\hline
\end{tabular}

The scale ranges from 1 (strongly disagree) to 6 (strongly agree).

\section{Individual level}

Overall the attitudes towards LCC is on the positive side (Table 5). The respondents especially agree to the statement that they like the actual idea of LCC and that LCC represents something valuable for them. They also perceive that LCC is a suitable tool in their work and that LCC provides them with relevant information. Thus, the results indicate that there seem to be fairly good conditions for a more widely use of LCC in renovation projects, both regarding users' qualifications and the LCC tool itself.

The individual rationales for using LCC cohere across the two respondent groups $\mathrm{A}$ and $\mathrm{B}$ and the results shows no statistically significant differences due to life cycle integration in project management routine.

\subsection{LCC practice in building renovation projects}

Answering questions related to LCC practice in building renovation projects the respondents were asked to consider a recently completed renovation project they had been involved in and use this to base their answers on.

\section{Sender and receiver of LCC results}

Among the respondents $(\mathrm{N}=42)$ that answered that they performed an LCC in a renovation project, sixty-one percent of the respondents stated that they used an LCC tool developed in-house of their organization. Of these, 7\% reported they used a tool developed by their own project team and 53\% reported using a tool developed elsewhere in their organization. $26 \%$ reported they used a publicly available computational tool. $7 \%$ stated they did not use any specific calculation tool and equally many that they do not know what tool that was used.

The results show that construction project managers are identified as key participants in the processes of developing decision support for renovation projects (see Table 6). The organization's internal energy coordinator and the facilities manager are also involved in these processes. Building design managers and consulting installation engineers are also involved to a relatively high degree. Environmental managers and environmental consultants
Table 6. Degree of participation by various actors in the process of developing decisional support for the renovation project

\begin{tabular}{|l|c|c|c|}
\hline \multicolumn{1}{|c|}{ Actor } & $\mathrm{N}$ & $\mathrm{M}$ & $\mathrm{Sd}$ \\
\hline Construction project manager & 71 & 5.52 & 0.86 \\
\hline Energy coordinator (internal) & 70 & 4.79 & 1.33 \\
\hline Property/facilities manager & 69 & 4.35 & 1.34 \\
\hline Consulting HVAC engineer & 67 & 4.15 & 1.53 \\
\hline Building design manager & 67 & 4.03 & 1.87 \\
\hline Consulting building engineer & 66 & 3.73 & 1.80 \\
\hline Top management & 69 & 3.71 & 1.75 \\
\hline Energy consultant & 68 & 3.63 & 1.75 \\
\hline Environmental official (internal) & 68 & 3.60 & 1.68 \\
\hline Architect & 68 & 3.50 & 1.89 \\
\hline Financial officer & 70 & 3.31 & 1.75 \\
\hline Building contractor & 69 & 3.16 & 1.85 \\
\hline Authorities & 67 & 2.82 & 1.69 \\
\hline Environmental consultant & 66 & 2.79 & 1.70 \\
\hline Politicians & 66 & 2.36 & 1.73 \\
\hline
\end{tabular}

The scale ranges from 1 (not at all) to 6 (extremely high).

and also financial officers come into play to a lesser extent. Politicians and authorities are not seen as important participants in the process. Neither is the building contractor involved while participation is somewhat more likely for architects and consulting building engineers.

Of those respondents who stated that an LCC calculation was made, $41 \%$ answered that the unit or group they belonged to did the calculation. $26 \%$ stated it was someone else in their organization that performed the calculation and $21 \%$ hired a consultant for the calculation. Twelve percent stated that they did it by themselves.

The respondents were also asked to state whom they viewed as receivers of the results (Table 7). It is interesting to note that one of LCC's most important functions is reported to be establishing greater credibility for the decision (see Table 4), while respondents also report they themselves or their own project team are the primary recipients of LCC calculation results. Politicians, authorities 
Table 7. Primary recipient of the LCC results

\begin{tabular}{|l|c|c|c|c|}
\hline \multicolumn{1}{|c|}{ Actor } & $\mathrm{N}$ & $\mathrm{M}$ & $\mathrm{Sd}$ & Rank \\
\hline The project team & 42 & 8.52 & 1.38 & 1 \\
\hline Myself & 42 & 7.88 & 2.28 & 2 \\
\hline Management staff & 42 & 7.76 & 2.05 & 3 \\
\hline Managers & 42 & 7.12 & 1.56 & 4 \\
\hline $\begin{array}{l}\text { Operation/facility } \\
\text { administrators }\end{array}$ & 42 & 6.93 & 1.67 & 5 \\
\hline Customer/client & 42 & 4.48 & 1.78 & 6 \\
\hline Suppliers & 42 & 3.88 & 1.50 & 7 \\
\hline $\begin{array}{l}\text { Residents/resident } \\
\text { organisations }\end{array}$ & 42 & 2.55 & 1.47 & 8 \\
\hline Politicians & 42 & 2.43 & 3.06 & 9 \\
\hline Authorities & 42 & 1.81 & 1.74 & 10 \\
\hline Accountants/auditors & 42 & 1.64 & 1.50 & 11 \\
\hline
\end{tabular}

The scale ranges from 1 (least important recipient) to 11 (most important recipient).

and accountants/auditors are ranked much lower. LCC and LCC calculations are thus primarily viewed as inhouse project tools.

\section{Key input parameters used in LCC calculation}

Regarding the source for input data, $35 \%$ of the respondents stated they primarily used estimates based on the project team's previous experience. $30 \%$ stated they performed a one-off thorough inventory specifically for the renovation project in hand. A smaller number said they downloaded historical data from in-house databases (19\%) and even fewer used general industry template data (7\%).

The length of lifetime selected strongly impacts the LCC calculation. The longer this is, the greater the uncertainty built into the calculation. But, shorter lifetimes risk missing a majority of costs with long-term significance. The survey finds that a majority of respondents state they use a lifetime longer than 21 years in their LCC calculation (53\%). 30\% indicate they use 11-20 years, and 9\% 4-10 years. No answers were for $1-3$ years, and $7 \%$ said they do not know the lifetime used.

The discount rate used in an LCC calculation has significant impact on the results, especially when using a present value method to compare cash flows over time. The higher the discount rate, the lower the value of future costs in the calculation. In literature, some researchers use a zero percent discount for environmental investments, arguing that future costs will have a value equal to the cost that would be due if the payment were made today. Others advocate that different discount rates should be used for different cost items depending on the future environmental impact of that particular item. None of the respondents indicated they used a zero percent discount rate. An overwhelming majority $(68 \%)$ used a rate set centrally in their organization for investments in general, that is, the same rate used for a standard investment calculation with short time perspectives. A few respondents used an industrywide standard rate (5\%) and a similar number used a calculation method that does not consider cost of capital, as with the payback method. $12 \%$ of respondents indicated they considered cost of capital as a variable for application in sensitivity analyses. $12 \%$ of respondents answered that they did not know the interest rate used. An observation here is that the option to vary the interest rate depending on project type, which nearly $25 \%$ agreed was preferable, would involve some kind of negotiation as to the interest rate used. However, no respondents stated the discount rate was set through a negotiation process.

\section{Discussion and conclusion}

This study shows that real estate- and property owners in general have a positive attitude towards life cycle thinking. LCC is perceived as a valuable and suitable tool and provider of increased control in renovation investment situations. As instrumental rationale for using LCC, the respondents mention LCC's ability to offer a comparative basis for different investment solutions, that the calculation results show the most cost effective solutions in a long-term perspective and indicate rising energy costs. All above is consistent with LCC's built-in theoretical economics logic and demonstrates that LCC is indeed viewed as the financial instrument suggested in literature (Farr, 2011; Dhillon, 2013). On an operational level, LCC is perceived as having many different functions and thus providing enough flexibility for practical use in a renovation context. A consistent and familiar terminology was also a strong rationale for using LCC. Increased time and costs for applying and using LCC are often described as barriers for sustainability practices (Häkkinen \& Belloni, 2011; Opoku \& Ahmed, 2014), but were not seen as major barriers here, especially not among the group that included life-cycle thinking into their project management routines.

Dividing the respondents into two groups depending on if they have included life cycle management into their project management routines (group A) or not (group B), enabled us to investigate if this integration has had effect on attitudes towards LCC. Figure 1 present perceived rationales for LCC use where there are statistically significant differences between the two groups. In general group $\mathrm{B}$ tends to see more hindrances than group A that feels that using LCC aligns well with how they work. This is for example mirrored in the instrumental function on LCC, where group A considers it more useful to direct investment decisions than group $B$.

The results show that managerial rationales in terms of the extent to which LCC is advocated and used by others affects the extent to which LCC is used. Comparing group $\mathrm{A}$ and $\mathrm{B}$, the first is foremost driven by management directives and internal demands while the latter seem to be industry driven. Group A also sees knowledge in project team and involved project managers together with that long-term perspectives and solutions is favored within the organization as key reasons to the adoption of LCC in 


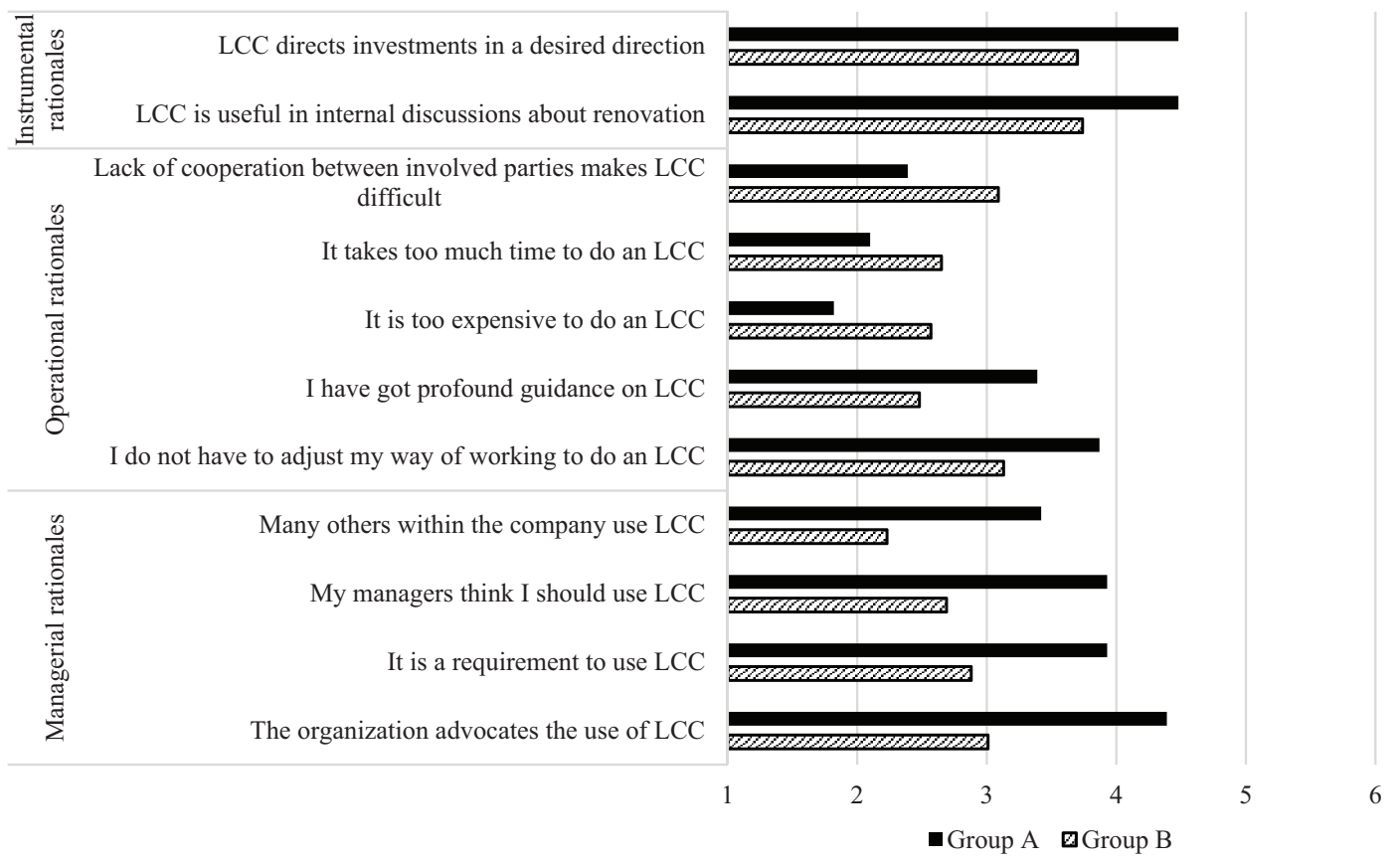

Figure 1. Statistically significant differences between Group A and Group B in terms of perceived rationales or non-rationales for LCC use

renovation, whereas group B emphasizes separated money bags as reason not to. The above tells us that to increase the use of LCC, as well as a having a realistic idea what LCC can do or not, companies should strive to establish a culture that advocates a continuous use of LCC, both within the organization but also through joint industry initiatives.

Although the respondents have a general positive attitude towards LCC, and perhaps also expectations of what it can do, our results display a fragmented and undeveloped view on how LCC is used in practice. This reveals that the attractiveness of LCC rather relates to a sense of familiarity with the economic format than getting well-grounded calculation results (cf. Gluch \& Baumann, 2004). The awareness regarding effects from assumptions made in the financial analysis seems inadequate and the use of LCC simplistic in comparison to the tools developed and proposed in research literature. The calculations, for example, were built on rough cost estimates based on 'common sense' within foremost a closed project team, a general discount rate for all kinds of investments was used, and sensitivity analysis to account for future uncertainty was seldom applied. In addition, in many cases the project teams performed their own LCC calculation while at the same time being the primary recipients of the results from it. Although less familiar with the LCC terminology and in general more hesitant to LCC use, Group B seem to like the actual idea of LCC more than group $\mathrm{A}$. The reason behind this cannot be determined based on the study. However, a possible explanation might be that this reflects an even more immature and idealistic view on LCC among group B than with Group A. A view that maybe has started to be challenged for Group A respondents when incorporating LCC in their project management routines.

Project managers and energy managers were viewed as the most influential parties in the decision-making processes, whereas environmental and financial managers had limited involvement, which further adds to a naivety in its use as a financial accounting instrument. Similar to Olsson et al. (2015) and Ludvig, Stenberg, and Gluch (2013) we conclude that the ways sustainability issues are addressed in renovation decisions may largely depend on the skills and wills of individual project managers.

Our findings also confirm what has previously been shown, that individuals across the industry have developed their own way of conducting an LCC (Olubodun, Kangwa, Oladapo, \& Thompson, 2010). Taken together, we discern a self-supportive pattern, where LCC is performed by the project group to legitimize decisions and strengthen support for a preferred design solution. Even if LCC attempt to capture costs across an entire life cycle, decisions still risk failing to consider perspectives of various stakeholders involved in a renovation project (Swarr et al., 2011). As consequence, the opportunity to widen the views and make more holistic and strategic decisions, something proclaimed as being the very essence of LCC in contrast to regular investment calculus, might get lost. After all, the main idea of LCC, with its life cycle approach, is to support strategic decision making. The dominant involvement by project and energy managers coupled with the relative absence of environmental managers in shaping the calculations, suggest that in practice LCCs represent a relatively narrow focus and not the long-term 
and comprehensive take on environmental and sustainability issues as promoted in research. Instead of being perceived as a fine-tuned calculation instrument, LCC is viewed as a credibility provider and as informative mean to explain and/or facilitate discussions regarding longterm issues within the organisation, i.e. LCC serves as a communicative instrument giving legitimacy to the renovation project. In sum, LCC calculations give practitioners a sense of a systematic and rational decision-making process rather than supporting the decisions with detailed figures. Thereby, the choice of, for example, the discount rate also becomes less important.

The above points towards the importance for toolmakers to move beyond a functionalist view on LCC and adopt an interpretive view that considers actions and sense-making of individuals in their shaping of tools in practice, similarly to what Rex and Baumann (2008) concluded about LCA. LCC practice in building renovation takes place in a context of multiple and partly competing institutional logics - those of economics, project practice, energy efficiency and sustainability (Hill, Lorenz, Dent, \& Lützkendorf, 2013). Renovation decisions are thus exposed to long-term demands on energy efficiency, governmental and corporate sustainability directives, while being governed by short-term corporate financial goals and policies related to profit and return on investment (Higham et al., 2015). These two perspectives follow different logics, in that they are associated with different organizing principles where each requires a different set of behaviours from those involved (Reay \& Hinings, 2009). In addition, there is also the logic of project management, which is associated with temporality, unique one-off nature, context dependency, and short-term cost frames. Research on LCC has so far neglected the multiplicity of logics that are inherent in LCC practice. As noted when comparing practitioners group $\mathrm{A}$ and $\mathrm{B}$, the ones who included LCC in their project management routines were also the most positive to integration of strategic functions with project management functions. This emphasise the importance of not isolating LCC to individual renovation project, and instead lift it to a strategic property management level.

We, as do Robichaud and Anantatmula (2010), point to a relationship between various communicative and collaborative actions and integrated life-cycle thinking in project practices worthy of further exploration. Among these actions and as key for more conscious adoption of LCC in renovation projects (cf. Häkkinen \& Belloni, 2011), our study especially points out the importance of giving project managers' more opportunities to contribute to long-term strategic decisions and to raise their knowledge and ability to grasp the bigger picture.

In the literature, the limited adoption of LCC in practice is often seen as resulting from a lack of standards, formal guidelines and useable software (Arditi \& Messiha, 1999; Olubodun, Kangwa, Oladapo, \& Thompson, 2010; Goh \& Sun, 2016). However, this lack of consistent rules did not stop our respondents from performing LCC calcu- lations, as we identified an established use of LCC among them. The question remains whether or not industry standards for LCC is an answer, considering that renovation projects make a contextual, fragmented, and complex application context for LCC, and even more so given the diversity of other contexts exhibited over time (Korpi \& Ala-Risku, 2008). An alternative to industry standardization is for organizations to strive for more consistency over time as suggested by Lindholm and Soumala (2007). Our study confirms the importance of consistency as it shows a relationship between how long LCC has been used in a firm/organization and the proportion of projects in which LCC is used. By continuously practicing long-term cost accounting and collecting cost history data, an organization can develop life cycle costing throughout the organization into a long-term project. By persistently working with LCC, learning and knowledge on sustainable building might also be developed and shared across organizational boundaries and thus become less dependent on specific individual decision-makers.

This study is limited to Swedish real estate organizations. A comparative study of rationales behind LCC use in different countries would be of interest setting these results into a global perspective. While much of previous research have aimed at developing more sophisticated LCC models and tools, our results show that managers' interest in these refinements seem limited. Our recommendation is that future research should look beyond tool development and applications. This is not to say that such development should be abandoned, however, it is of little use unless practitioners adopt and use these applications as intended. Since a quantitative survey is limited in its ability to provide in-depth understanding regarding actual use of LCC we suggest complementary qualitative studies of real life property management practices. Further and in-depth studies of how decision-making and property management strategies are aligned in relationship to tools, roles and responsibilities would contribute to an increased understanding of this. Thus, paying greater attention to the behavioural aspects of decision making processes, to the communicative dimensions within LCC practices and the possible effects from this is suggested to be a fruitful way forward. After all, it is people that make decisions not tools.

\section{References}

Arditi, D., \& Messiha, H. M. (1999). Life cycle cost analysis (LCCA) in municipal organizations. Journal of Infrastructure Systems, 5(1), 1-10.

https://doi.org/10.1061/(ASCE)1076-0342(1999)5:1(1)

Arja, M., Sauce, G., \& Souyri, B. (2009). External uncertainty factors and LCC: a case study, Building Research and Information, 37(3), 325-334. https://doi.org/10.1080/09613210902863609

Ástmarsson, B., Jensen, P. A., \& Maslesa, E. (2013). Sustainable renovation of residential buildings and the landlord/tenant dilemma, Energy Policy, 63, 355-362.

https://doi.org/10.1016/j.enpol.2013.08.046 
Brown, N. W., Malmqvist, T., Bai, W., \& Molinari, M. (2013). Sustainability assessment of renovation packages for increased energy efficiency for multi-family buildings in Sweden. Building and Environment, 61, 140-148. https://doi.org/10.1016/j.buildenv.2012.11.019

Caccavelli, D., Krigsvol, G., Thamling, N., \& Jaarto, P. (2005). LCC-REFURB guidebook: integrated planning for building refurbishment taking life-cycle costs into account. European Commission, Brussels.

Carifio, J., \& Perla, R. J. (2007). Ten common misunderstandings, misconceptions, persistent myths and urban legends about likert scales and likert response formats and their antidotes. Journal of Social Sciences, 3(3), 106-116. https://doi.org/10.3844/jssp.2007.106.116

D’Incognito, M., Costantino, N., \& Giovanni, C. M. (2015). Actors and barriers to the adoption of LCC and LCA techniques in the built environment. Built Environment Project and Asset Management, 5(2), 202-216.

https://doi.org/10.1108/BEPAM-12-2013-0068

Davis, F. D. (1989). Perceived usefulness, perceived ease of use, and user acceptance of information technology. MIS Quarterly, 13(3), 319-340. https://doi.org/10.2307/249008

Dhillon, B. (2013). Life cycle costing: techniques, models and applications. Routledge.

Ding, G. K. (2008). Sustainable construction - the role of environmental assessment tools. Journal of Environmental Management, 86(3), 451-464.

https://doi.org/10.1016/j.jenvman.2006.12.025

Farr, J. V. (2011). Systems life cycle costing: economic analysis, estimation, and management. CRC Press.

Flores-Colen, I., \& De Brito, J. (2010). A systematic approach for maintenance budgeting of buildings façades based on predictive and preventive strategies. Construction and Building Materials, 24(9), 1718-1729.

https://doi.org/10.1016/j.conbuildmat.2010.02.017

Gluch, P. (Ed.) (2014). Perspektiv på LCC - en bok om långsiktiga beslut och styrning vid hållbar och energieffektiv renovering av byggnader. Report 2014:3, Civil and Environmental Engineering. Chalmers.

Gluch, P., \& Baumann, H. (2004). The life cycle costing (LCC) approach: a conceptual discussion of its usefulness for environmental decision-making. Building and Environment, 39(5), 571-580. https://doi.org/10.1016/j.buildenv.2003.10.008

Gluch, P., \& Gustafsson, M. (2015, August). Acceptance and use of LCC as a decision support tool for renovation investments. Proceedings of the International Conference on Construction and Real Estate Management (ICCREM 2015) (pp. 821-828). Luleå, Sweden. https://doi.org/10.1061/9780784479377.095

Goh, B. H., \& Sun, Y. (2016). The development of life-cycle costing for buildings. Building Research and Information, 44(3), 319-333. https://doi.org/10.1080/09613218.2014.993566

Häkkinen, T., \& Belloni, K. (2011). Barriers and drivers for sustainable building. Building Research and Information, 39(3), 239-255. https://doi.org/10.1080/09613218.2011.561948

Higham, A., Fortune, C., \& James, H. (2015). Life cycle costing: evaluating its use in UK practice. Structural Survey, 33(1), 7387. https://doi.org/10.1108/SS-06-2014-0026

Hill, S., Lorenz, D., Dent, P., \& Lützkendorf, T. (2013). Professionalism and ethics in a changing economy. Building Research and Information, 41(1), 8-27.

Junghans, L. (2013). Sequential equi-marginal optimization method for ranking strategies for thermal building renovation. Energy and Buildings, 65, 10-18. https://doi.org/10.1016/j.enbuild.2013.05.028
Kaklauskas, A., Zavadskas, E. K., \& Raslanas, S. (2005). Multivariant design and multiple criteria analysis of building refurbishments. Energy and Buildings, 37(4), 361-372. https://doi.org/10.1016/j.enbuild.2004.07.005

Kirkham, R. J. (2005). Re-engineering the whole life cycle costing process. Construction Management and Economics, 23(1), 9-14. https://doi.org/10.1080/01446190410001678765

Korpi, E., \& Ala-Risku, T. (2008). Life cycle costing: a review of published case studies. Managerial Auditing Journal, 23(3), 240-261. https://doi.org/10.1108/02686900810857703

Legris, P., Ingham, J., \& Collerette, P. (2003). Why do people use information technology? A critical review of the technology acceptance model. Information and Management, 40(3), 191204. https://doi.org/10.1016/S0378-7206(01)00143-4

Lindholm, A., \& Suomala, P. (2007). Learning by costing: sharpening cost image through life cycle costing?. International Journal of Productivity and Performance Management, 56(8), 651-672. https://doi.org/10.1108/17410400710832985

Love, P., \& Bullen, P. A. (2009). Toward the sustainable adaptation of existing facilities. Facilities, 27(9/10), 357-367. https://doi.org/10.1108/02632770910969603

Ludvig, K. (2013). Making sense of and managing energy targets in public construction-client organisations (Licentiate degree thesis). Chalmers Univerity of Technology.

Ludvig, K., Stenberg, A.-C., \& Gluch, P. (2013). The value of communicative skills for developing an energy strategy. Building Research and Information, 41(6), 611-621. https://doi.org/10.1080/09613218.2013.800735

Mjörnell, K., Boss, A., Lindahl, M., \& Molnar, S. (2014). A tool to evaluate different renovation alternatives with regard to sustainability. Sustainability, 6, 4227-4225. https://doi.org/10.3390/su6074227

Morrissey, J., Meyrick, B., Sivaraman, D., Horne, R., \& Berry, M. (2012). Cost-benefit assessment of energy efficiency investments: accounting for future resources, savings and risks in the Australian residential sector. Energy Policy, 54, 148-159. https://doi.org/10.1016/j.enpol.2012.11.005

Oduyemi, O. I. (2015). Life cycle costing methodology for sustainable commercial office buildings ( $\mathrm{PhD}$ degree thesis). University of Derby, UK.

Olsson, S., Malmqvist, T., \& Glaumann, M. (2015). Managing sustainability aspects in renovation processes: interview study and outline of process model. Sustainability, 7(6), 6336-6352. https://doi.org/10.3390/su7066336

Olsson, S., Malmqvist, T., \& Glaumann, M. (2016). An approach towards sustainable renovation: a tool for decision support in early project stages. Building and Environment, 106, 20-32. https://doi.org/10.1016/j.buildenv.2016.06.016

Olubodun, F., Kangwa, J., Oladapo, A., \& Thompson, J. (2010). An appraisal of the level of application of life cycle costing within the construction industry in the UK. Structural Survey, 28(4), 254-265. https://doi.org/10.1108/02630801011070966

Opoku, A., \& Ahmed, V. (2014). Embracing sustainability practices in UK construction organizations. Built Environment Project and Asset Management, 4(1), 90-107. https://doi.org/10.1108/BEPAM-02-2013-0001

Palm, J., \& Reindl, K. (2016). Understanding energy efficiency in Swedish residential building renovation: a practice theory approach. Energy Research \& Social Science, 11, 247-255. https://doi.org/10.1016/j.erss.2015.11.006

Park, S. H. (2009). Whole life performance assessment: critical success factors. Journal of Construction Engineering and Management, 135(11), 1146-1161. https://doi.org/10.1061/(ASCE)CO.1943-7862.0000090 
Reay, T., \& Hinings, C. R. (2009). Managing the rivalry of competing institutional logics. Organization Studies, 30(6), 629652. https://doi.org/10.1177/0170840609104803

Rex, E., \& Baumann, H. (2008). Implications of an interpretive understanding of LCA practice. Busines Strategy and Environment, 17, 420-430. https://doi.org/10.1002/bse.633

Risholt, B., Time, B., \& Hestnes, A. G. (2013). Sustainability assessment of nearly zero energy renovation of dwellings based on energy, economy and home quality indicators. Energy and Buildings, 60, 217-224.

https://doi.org/10.1016/j.enbuild.2012.12.017

Robichaud, L. B., \& Anantatmula, V. S. (2010). Greening project management practices for sustainable construction. Journal of Management in Engineering, 27(1), 48-57. https://doi.org/10.1061/(ASCE)ME.1943-5479.0000030

Schaltegger, S., Müller, K., \& Hindrichsen, H. (1996). Corporate environmental accounting. Chichester: Wiley.

Sharma, A., Saxena, A., Sethi, M., \& Shree, V. (2011). Life cycle assessment of buildings: a review, Renewable and Sustainable Energy Reviews, 15(1), 871-875. https://doi.org/10.1016/j.rser.2010.09.008

Swarr, T. E., Hunkeler, D., Klöpffer, W., Pesonen, H.-L., Ciroth, A., Brent, A. C., \& Pagan, R. (2011). Environmental life-cycle costing: a code of practice. International Journal of Life Cycle Assessment, 16(5), 389-391. https://doi.org/10.1007/s11367-011-0287-5

Thuvander, L., Femenias, P., Mjörnell, K., \& Meiling, P. (2012). Unveiling the process of sustainable renovation. Sustainability, 4(6), 1188-1213.https://doi.org/10.3390/su4061188

Wang, N., Chang, Y.-C., \& Nunn, C. (2010). Lifecycle assessment for sustainable design options of a commercial building in Shanghai. Building and Environment, 45(6), 1415-1421. https://doi.org/10.1016/j.buildenv.2009.12.004

Wang, W., Zmeureanu, R., \& Rivard, H. (2005). Applying multiobjective genetic algorithms in green building design optimization. Building and Environment, 40(11), 1512-1525. https://doi.org/10.1016/j.buildenv.2004.11.017

Woodward, D. G. (1997). Life cycle costing - theory, information acquisition and application. International Journal of Project Management, 15(6), 335-344. https://doi.org/10.1016/S0263-7863(96)00089-0

Zhang, X., Platten, A., \& Shen, L. (2011). Green property development practice in China: costs and barriers. Building and Environment, 46(11), 2153-2160.

https://doi.org/10.1016/j.buildenv.2011.04.031 